\title{
Most-Wanted English Learning Mobile Apps
}

\author{
Mokhammad Nizzam ${ }^{1}$ \\ ${ }^{1}$ Institut Pesantren Kh. Abdul Chaim Pacet, Mojokerto Indonesia \\ Email:snizzam.tep@gmail.com
}

Submitted: 14-01-2020 Revised : 11-03-2020 Accepted: 15-04-2020

\begin{abstract}
Abstrak: Covid-19 pandemic has contributed a great encouragement for autonomous learners in using mobile learning to learn foreign languages, including English. Geared under qualitative design, the present study aims to find out the availability of mobile apps that most people use in learning English. It concerns to review and make comparisons among the top three most popular apps gathered on the Google Playstore list to investigate what they teach, how they teach, and what technology they use in order to figure out on which aspects they are distinct to each other and on which they are similar, where are they lacking, and what they do well. The results point out that the apps were developed in such easy and fun ways of learning with various materials, ie daily life situations, and stories. Though enriched with vast exercises in receptive skills, they are commonly offered limited practice in productive skills.
\end{abstract}

Keywords: EFL, MALL, Learning Apps

https://doi.org/10.54069/attadrib.v3i1.181

How to Cite Nizzam, M (2021). Most-Wanted English Learning Mobile Apps. Attadrib: Jurnal Pendidikan Guru Madrasab Ibtidaiyah, 3 (1) 43-52

\section{INTRODUCTION}

Advances in information technology have a disruptive influence on various aspects of human life, including education. The paradigm shift in the implementation of learning has been running for more than two decades on a large scale, which was initially carried out conventionally in the classroom to online learning without the limitations of space and time (Alhadhrami,2017; Alkhezzi \& Al-Dousari, 2016). Hi-tech devices, such as smartphones, have become the trend of learning for millennial learners. Bringing the gadgets anywhere and anytime is their peculiar characteristics nowdays.

Smartphones are able to combine flexibility, accessibility and interactivity in forms of mobile apps to facilitate online language learning via direct access, relevant resources, prevalent reviews, and sufficient exercises (Dai et al., 2018; Mospan, 2019). Their usage among foreign language learners has become a major trend, especially those targeting English, across the globe. This overwhelming trend has also shifted greatly from teacher-centered learning, the conventional one, into a self-regulated and autonomous one. Through this approach, students can freely select various learning resources to efficiently deploy according to their learning style and most convenient time. For those reasons, developing language learning apps should meet the following criteria(Barcomb et al., 2018).

1) Offering adequate number of oral and written texts

2) Contextual use of target language

3) Displaying sufficient examples of language use 
4) Containing enough activities and exercises

5) Interactive, attractive and interesting forms of activities

6) All units and parts are complementary

7) Stimulus and feedback are frequently given

8) Regular updates on contents

In developing a technology to support language learning, the developer integrates language learning methods in the application and its website. Some methods commonly used in this purpose are Grammar Transalation Method (GTM), Audio Lingual Method ( ALM), Direct Method (DM), Reward \& Punishment (R\&P), and Community Language Learning (CLL) (Larsen-Freeman \& Anderson, 2011; Richards \& Rodgers, 1986).

As the oldest language learning method, the Grammar Translation Method focuses on language transfer and reading skills. The mastery of the target language is measured by the learner's ability to translate vocabulary separately and contextually from the target language to the mother tongue, and vice versa. The implication of this method in application development is the presence of a bilingual dictionary feature and translation assistance, both in terms of appearance and teaching material (Sierra \& de Alcalá, 2016). The use of native languages according to GTM is an absolute thing and is an important component. Grammar gets a dominant portion in GTM, because the focus is on understanding written texts.

In contrast, Direct Method (DM) encourages students to always communicate actively in the target language, without involving any native language. It aims to avoid the influence of native languages in understanding the target language obtained (Richards \& Rodgers, 1986). To convey new vocabulary, DM utilizes realia, images, and other media. Grammar is hardly focused on DM because vocabulary is the key to being able to communicate. The application of DM in a mobile application is a monolingual dictionary and the unavailability of translating material features and display applications other than in the target language.

Initially the Audio Lingual Method (ALM) was applied in military education, so it was also known as the army method. This language learning method is implemented by increasing the practice and practice of the target language in both oral and written forms, so students are accustomed to communicating like native speakers of the target language (Larsen-Freeman \& Anderson, 2011). Some principle in ALM are mimicry (imitating the source), drilling (frequent repetition), completion (completing cloze pricedure) and rejoinder(give the right answer to the question). In relation to the development of language applications, users must be given a lot of practice and practice, both oral and written. Students are asked to imitate native speakers (audio from the application) precisely and repeatedly so that they can communicate like native speakers.

The R\&P method is one form of application of behavioristic learning theory that aims to provide stimulus to students to better demonstrate the desired response in learning objectives (Schunk, 2012). The application in developing learning applications is usually motivational which encourages students to answer the exercises correctly and avoid mistakes. Game availability is also a form of applying this theory.

Community Language Learning (CLL) is a language teaching method that involves all students working together in developing the language skills they want to learn (Schunk, 2012). The idea of CLL originates from the basic idea that the use of language is not only to communicate languageally, but also includes physical reactions, thoughts and desires of all students. The teacher in CLL functions as a facilitator in a community. The teacher must be active to help students overcome their difficulties in learning, starting from translating new vocabulary, giving feedback, reflecting on activities, and guiding them in developing oral and written texts. Implementation of CLL in learning applications in the form of the availability of social media features,sharing, feedback, reflection and compilation of texts. 


\section{METHODE}

Review the English learning application based on several criteria for evaluating differences and similarities between the three applications. List of English learning applications obtained from Google Playstore services . There are dozens of programs in the specifications of this field. Because of the reason for the focus of this study, only three applications were chosen to be evaluated, namely Busuu, Hello-Hello and Learn English .

As a step, an investigation is carried out on the application developer and learning material. Then, an analysis is carried out on the learning method, motivation and the type of feedback used in the program. Furthermore, the researchers saw the application for themselves to find out the types of language components being taught, the level of teaching material, types of training, availability of free and paid features, popularity and comments from users. Finally, researchers will also conclude their experiences and perceptions of the application in material and technological aspects. These criteria are summarized in Table 1.

\begin{tabular}{|l|l|l|}
\multicolumn{1}{|c|}{$\begin{array}{c}\text { Background } \\
\text { \& Pedagogy }\end{array}$} & \multicolumn{1}{|c|}{$\begin{array}{c}\text { Teaching \& } \\
\text { Training Materials }\end{array}$} & \multicolumn{1}{c|}{ Platform \& Popularity } \\
\hline - The developer & \multicolumn{1}{|c|}{ What is taught? } & - Platform (download, web-based) \\
- Method & - Vocabulary & - Price (free, paid) \\
- Feedback & - Listen & - Level \\
- Motivation & - Reading & - Popularity (download rating, usage rating, \\
- Feedback & - Write & user comments) \\
& - Speak out & \\
\hline
\end{tabular}

\section{FINDINGS AND DISCUSSION}

\section{BUSUU}

This application is a part of its website version (www.busuu.com ) which is an online language community with members of more than 25 million people who offer learning 12 foreign languages. According to information from the provider website, the development of this application begins with the developers ' equipment about English teaching methods that are too expensive and boring, so they decide to create their own teaching materials with sound and images that allow their users to learn directly from native speakers at no charge to the some of the material. Users can access features in full by paying Premium membership at a cheaper price than face-to-face courses in the real world.
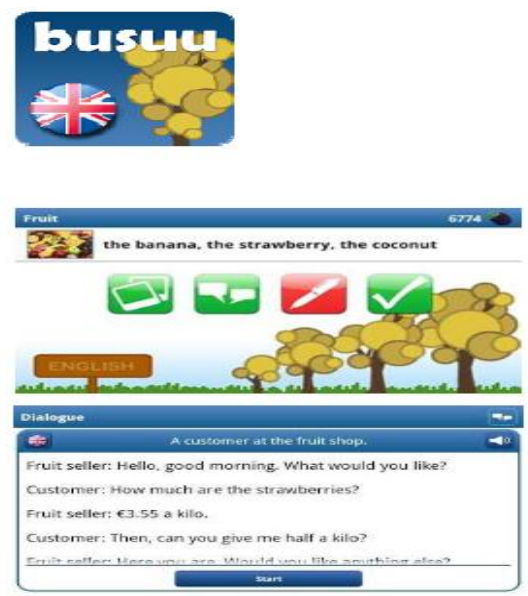

Figure 1. Busuu Display 
As a complement to the application version, Busuu has also developed a learning website that provides learning 12 foreign languages. To create interesting learning, the website version combines games, language learning and social media. Users will get Buusu fruit when completing a part of the teaching material, and provide corrections to the results of other users' training. The number of fruits received by all users in one community can be seen on the screen so that it can be an encouragement for all participants. The collection of fruit can be used as a capital challenge to partner users to compete in completing a material. The winner will get a fruit transfer as a number of his opponent's losing bets.

Another motivational feature is the language park where users can see the progress made while attending an online English course at Busuu. Every mistake made will be recapitulated and become a pest insect. This encourages players to play more carefully so that the pest does not eat their language tree. Funny animated awards can also be obtained by users after completing tests and courses, as well as providing corrections to other user exercises. Instead, Busuu sends regular messages to users to stay motivated to learn. The smartphone application can be synchronized with the website so that the exercises done on the cell phone can affect the tree and fruit of Busuu.

After downloading, this application can run without an internet connection. Users can use the application on a cellphone without updating on the website. Even so, users can register on the Busuu website which offers online language courses and synchronizes their progress in the application with the progress of the online courses on the website.

The mobile version of the application does not offer all the functions and materials available on the website version, such as pronunciation exercises, pdf version teaching materials, and podcasts. Even so, the material available on the mobile application is very substantive and covers 150 topics about daily life. Busuu teaching material is intended for beginner and upper secondary level (A1-B2), and includes 3 thousand vocabularies and phrases, if buying a premium membership.

In the four skill levels (A1-B2), there are many units that cover daily and grammatical topics. Each topic consists of 3 or 4 exercises. The first exercise is in the form of vocabulary exercises with rock flashcards containing certain words or images pronounced by native speakers. Secondly, an exercise in the form of written and oral dialogues that asks users to answer 3 multiple choice questions relating to information in the dialogue. The third exercise is writing practicewith guide questions and pictures to make it easier for users to write answers sent directly to the community to get feedback from native speaker users. While the last exercise contains a review of all units with three types of questions: matching written phrases with spoken expressions, composing sentences of random words, and matching English phrases with their equivalents in the original language. User errors will be saved in a tab called my mistake for review and re-training. It is important to know that there is no explanation about grammatics in this application, although it is always practiced by users in every exercise.

The price of subscribing to the Busuu program can be seen on the website www.busuu.com . Within a few days after registration, Busuu offers discounts for premium accounts with 2 variants: regular ( $€ 5.83$ / IDR 92,545.00) and plus ( $€ 6.66$ / IDR 105,722.00). The second type has advantages in setting study patterns, coverage up to 12 languages and official Busuu certificates. In the mobile application, each additional teaching material costs $€$ 3.99 (Rp. 63,338). The free version will be interspersed with additional advertisement material, while the premium account is ad-free.

In appearance, Busuu is very attractive, well organized and easy to navigate. However, often the keyboard feature is slightly constrained in adjusting the size which can interfere with writing exercises. Another technical problem is the language of instruction in applications that are limited to only 15 languages (including Indonesian). This causes difficulties in access by students with native languages other than the 15 languages. 
In general, Busuu is a language learning application that provides vocabulary and phrase exercises at short dialgo and sentence levels. The material and listening exercises are also on the same level. Although this application covers many topics in teaching and training material in each unit of study, there are no additional teaching materials and significant good feedback other than just an indication of color to determine right or wrong.

Hello-hello

Born in collaboration with The American Council of Teaching of Foreign Language ( ACFTL), the developer gave birth to an application that combines the concepts of language learning and social media. Following the American-style education system, Hello-Heloo helps users achieve functional knowledge of language in everyday contexts. Users are invited to practice all aspects of language to communicate in real life. New vocabulary is introduced in contexts that are as interesting and communicative as possible. Each unit is designed in stages in terms of difficulty and level of vocabulary, as well as mutually reinforcing what was discussed in the previous unit. The platform used to accommodate learners can practice according to their time and speed.

Hello-Hello does not deploy any prize or other features to motivate its users. The social media feature on its website offers and receives feedback on oral and written exercises, but this is not available in the application features. However, access to material that is easy and can be downloaded on mobile phones and practiced anywhere without an internet connection, strongly supports the autonomy and motivation of learners

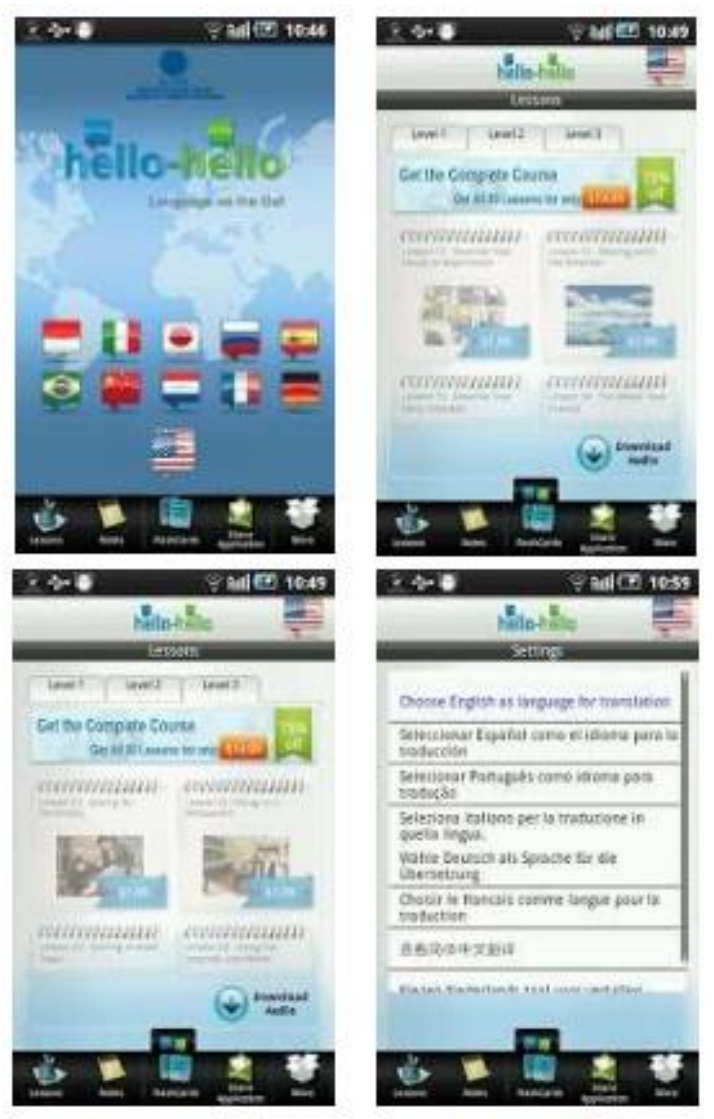

Figure 2 Hello-Helo

Teaching materials are arranged based on American-style conversation patterns with the aim of preparing students to be able to communicate in everyday situations. Material design is intended for beginner level (level A1-A2). There are 30 study units which are divided into 3 levels of proficiency and are provided in 7 languages. The English application offers 8 language versions. All material on the mobile application is the same as the material on the site and can be accessed offline. 
Similar to Busuu, users can interact on social media via audio, video or live chat with fellow users. Some training results can be sent to colleagues in 1 community for feedback from native speakers of the target language. All exercises can be answered verbally or in writing. However, this feature is not yet available in mobile applications.

Each unit of study is divided into 8 sessions. The first session always takes the form of dialogue dictated by an authentic voice that covers the situation and is practiced throughout the unit of study, for example a description of a family. The second session asks users to listen to the previous dialog again and read the transcript of the conversation at the same time. The third session provided an opportunity to listen to Dialgo for the third time while listening to an English transcript of dialogue and one of the 8 languages provided. In the fourth session, users are asked to listen to the dialogue by sentence and imitate it. In the fifth session, users listen to the dialogue, sentence by sentence, and are asked to write each sentence after it's spoken. The sixth session which is vocabulary material shows dialog transcripts with underlined parts of words and phrases. Users can click on the word or phrase that they want to know to find out its meaning and the collocation that appears in the pop-up window. Meanwhile, the seventh session of the users is shown one phrase and must choose tan answers exactly from the 4 available options. This exercise aims to see whether the users have understood the use of the phrase in real conversation. Finally, in the eighth session, users face 3 exercises: recording dialogue; write dialogue on the same topic; and record homemade dialogue. The three early exercises will be shared in the community to get feedback. The three exercises in this last session are only available in the website version, not in the application. When doing the exercises, users always have the opportunity to take notes and save them for later review. In addition to the subject matter, Hello-Hello provides flashcards with 19 different topics which are only supported by sound not images, because it only shows vocabulary writing.

The Hello-Hello learning website provides all teaching materials for free by account registration only. While the mobile application version only gives 1 free teaching material and asks the user to pay 29 remaining material at a price of $\$ 1.99$ (Rp. $28,098.80$ ) per purchase of 1 unit of material or $\$ 14.99$ (Rp. 211,658.80) for the entire teaching material.

The Hello-Hello mobile application has been downloaded hundreds of thousands of times with a rating of 3.1 on a scale of 5 . Some negative comments on the download homepage highlight its free application promos, but apparently pay to supplement all teaching material. By use, this application functions very nicely and is easy to navigate. The only thing that needs to be criticized is that the screen size is too small so that the dialog text doesn't fit and the font size is less proportional. This might be caused by the developer not considering setting different screen sizes for mobile phones.

Learning grammatical material is not focused in this application. In principle, users are more specialized in improving the four communication skills and vocabulary mastery without explaining how the grammatical rules system should be. Users without the basic capabilities of gratics and vocabulary will initially experience difficulties, but the application will motivate users to continue to complete and repeat the material repeatedly. Although an important motivational element in the form of social media is not available in the android application, teaching materials are well organized and practical because they provide lots of listening exercises and vocabulary in daily communication.

\section{Learn English}

The company behind the scenes of this application is Anspear which is a collaboration of FoneFonics engaged in mobile technology applications, along with Pearson Publishing with a wealth of experience in the use of technology in the world of education. Learn English has been reviewed by a group of English language teacher communities in charge of teaching immigrant families in the UK. The English- language ESOL (Adult Speaker of Other Languages) curriculum is used as the basis for developing this application. This is based on the reason that this 
application was originally designed for immigrants who need health insurance to public facilities in the UK.

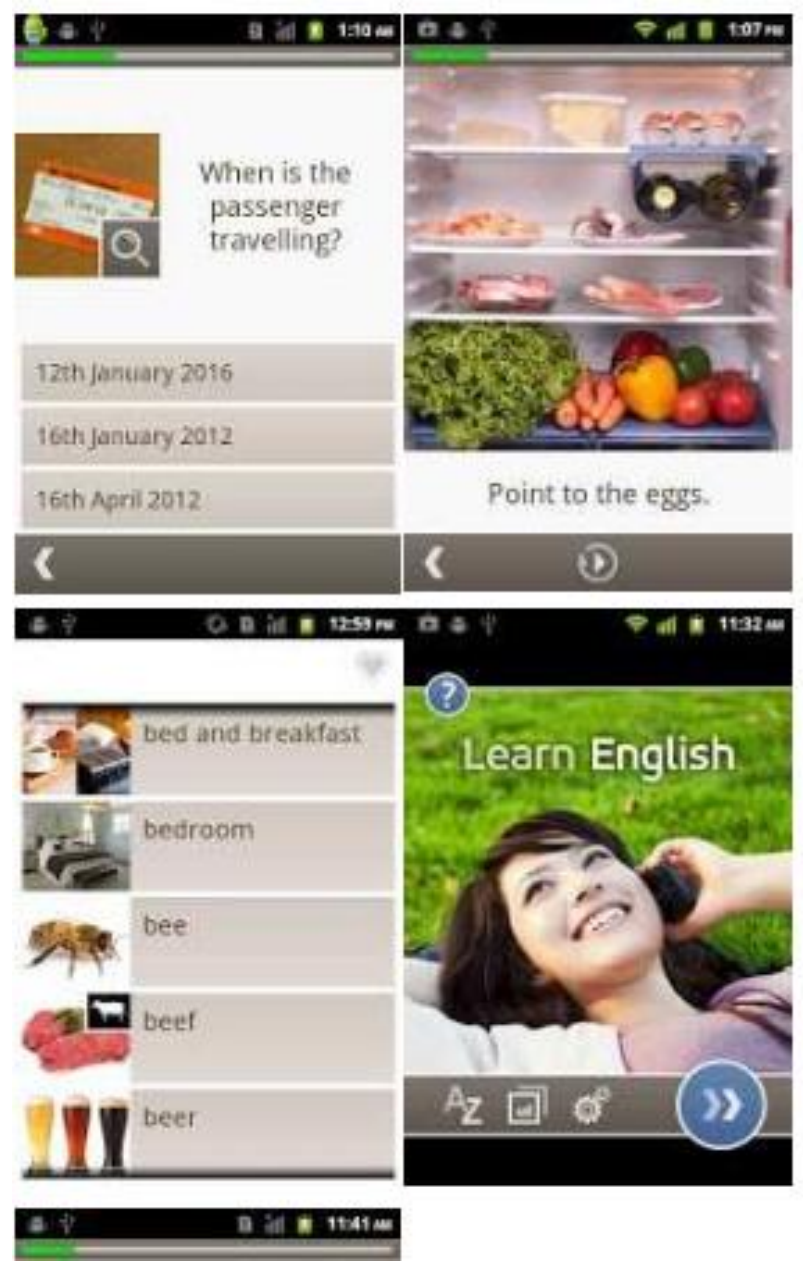

Figure 3 Display Learn English

Unlike the two previous applications, there are no special features that are interesting and motivating users in this application. There are no bonuses, rewards, games, and developments. The only feedback given is the color, the sound indicator of the validity of the answers and comments at the end of the exercise to repeat again or succeed in answering correctly. The only motivating thing is that this application runs offline and can be used anytime and anywhere after downloading all course material at a cheap price (€ 0.69 / Rp 10,894.22). Unlike the two previous applications, Learn English is stand-alone, not a part of the website. The level of ability taught is the beginner level (A1-A2).

Each of the 11 topics has different subtopics and exercises. The training items include vocabulary, spelling, word play, listening, reading, grammatics, word order and sentence patterns. The feedback given is an exercise in the form of an expression of successfully answering correctly or a request to repeat the exercise. Users can only advance to the next right number without being able to jump to item problems that are considered easy first. This application also provides a flashcard and a visual audo dictionary containing the vocabulary of exercises. In the dictionary, students can record their pronunciation and compare it with the native speaker version.

This application has been downloaded hundreds of thousands of times and has a rating of 4.4 on a scale of 5 . All comments on the homepage show positive things except complaints about payment for full material features. In terms of appearance, Learn English is very orderly, easy to navigate, fun and interesting. Students can choose 18 display languages. Interactive 
exercise similar to the previous two applications: multiple choice questions, fields and word order. The grammar rules are not explained, but are practiced. There is no feedback on the sound recording. Feedback for other exercises is limited to right and wrong. Speaking and writing skills do not get the focus of learning exercises in this application due to technical reasons and the lack of a website and social media version. In particular, the advantages of this application are the availability of flashcards and dictionaries with native speaker- style pronunciation .

\section{Learning methods}

In developing Busuu, the developers applied four methods of language learning. The GTM method is used in the material translation and application display features. ALM is applied with repetition and intense training. The game feature that makes the Busuu fruit a reward and loss as a punishment is an R\&P application. Finally, CLL provides social media that allows users to interact with each other by giving feedback and playing games.

Meanwhile, the Hello-Hello application applies 3 learning methods. The implementation of GTM is in the form of translating features for program display and material transcript in the original language. ALM is carried out with 8 solid and varied forms of exercises. Whereas Learn English, which does not provide display language transfer services and teaching materials, applies the DM method in an effort to understand the target language without the help of translators, ALM with a lot of practice and practice, as well as ESOL- style special curriculum .

\section{Motivation and Feedback}

In order for users to remain motivated in exporting applications, there must be compatibility with the user's ability level and interests. With these two things, students will definitely deploy the application enthusiastically.

Busuu has done the most innovative way to encourage its users to learn English. With the game and its Busuu fruit, this application encourages students to continue using this application, doing exercises with enthusiasm and accuracy so that their fruit stock does not decrease and increase. Reviewing the exercises that have been done will also increase the motivation of its users to increase fruit acquisition in subsequent exercises. The Hello-Hello and Learn English that do not have motivational features are constrained by technological problems, namely the design of application programming.

\section{Teaching \& Training Materials}

The variety of teaching materials offered by the three applications is very broad. Busuu has 161 study units, Hello-Hello with 30 units, and Learn English with 11 topics. Busuu and Learn English provide material covering a variety of topics in everyday life. While Hello-Hello is designed to mimic the variety of communication in real situations.

The three applications above turned out to have similarities in terms of teaching material. The underlying reason for this is technological limitations. A variety of similar exercises may be displayed in different ways, but generally consist of 3 types: multiple choice, filling, and arranging words. Although the feedback received was not guaranteed to be effective and constructive, Bussu and Hello-Hello made a breakthrough idea by distributing the results of the exercise to the community partners to obtain feedback .

The pronunciation aspect is only the focus of the Hello-Hello and Learn English applications in different ways. Hello-Hello asks the user to copy the example of the pronunciation heard, while Learn English compares the user's recording with the native speaker. This feature is unfortunately limited with no feedback as a suggestion to improve and improve the pronunciation of its users. The grammatics material is taught implicitly in all exercises.

The use of flashcards in all three applications is something that is commonly used for vocabulary learning. Unfortunately, only the spelling and writing flashcards on Learn English make it less attractive. All applications include short reading texts of around 2 to 10 sentences which are often supplemented by an audio version. The listening exercises have the same duration and the majority are equipped with transcripts for listening. 


\section{Application User Preferences}

There are many factors that influence the popularity of the application in addition to teaching material that is owned, such as compatibility, the amount of free jar material, the quality of the program, as well as the user's ability level. Of the three applications above, Busuu is the most popular. Not only language learning applications, other Busuu products also occupy the top 5 Google Playstore search listings. This shows that the popularity of the Busuu brand boosts the popularity of its language learning applications. The online community of Busuu, which has about 40 million members, is also increasing its popularity and becoming its own advantage over other applications that are not connected to the website.

Although not in the top rank, Hello-Hello and Learn English are also classified as popular applications that are downloaded by hundreds of thousands of people. In addition to the good rating, the minimal number of negative comments also greatly boosted the papularity of applications in Playstor

\section{CONCLUSSION}

Based on a review of the three applications above, the researcher shows that Busuu and Hello-Hello have aspects in common, namely in the application of learning methods (GTM, CLL, R\&P and CLL). Meanwhile, in the absence of motivational features, Hello-Hello is identical to Learn English. In general, all applications are designed for mobile learning that is fun and saves time and money. In addition to various shortcomings due to technological limitations, Busuu ranks first in terms of effectiveness and attractiveness of learning, while Learn English is the cheapest application with the most complete range of material.

This research shows that the practice of Mobile Assisted Language Learning is still constrained by many things besides pedagogy and technology. With the rapid development of the two disciplines, of course, the two obstacles can be overcome by conducting further research in the future $\%$

\section{REFERENSCES}

Alhadhrami, M. N. (2017). Using Mobile Phone Apps Inside and Outside The English Language Classroom by Undergraduate Students at Sultan Qaboos University: Attitudes, Practices and Challenges $\square$. 14.

Alkhezzi, F., \& Al-Dousari, W. (2016). The Impact of Mobile Learning on ESP Learners' Performance. The Journal of Educators Online, 13(2). https://doi.org/10.9743/JEO.2016.2.4

Barcomb, M., Grimshaw, J., \& Cardoso, W. (2018). Instructors as MALL engineers: Adapting, modifying, and creating mobile materials for listening practice. In P. Taalas, J. Jalkanen, L. Bradley, \& S. Thouësny, Future-proof CALL: language learning as exploration and encounters - short papers from EUROCALL 2018 (pp. 11-15). Research-publishing.net. https://doi.org/10.14705/rpnet.2018.26.805

Dai, G., Liu, Y., \& Cui, S. (2018). A Study on the Mobile Learning of English and American Literature Based on Wechat Public Account. English Language Teaching, 11(6), 47. https://doi.org/10.5539/elt.v11n6p47

Larsen-Freeman, D., \& Anderson, M. (2011). Techniques and principles in language teaching (3rd ed). Oxford University Press.

Mospan, N. (2019). Mobile Teaching and Learning English - A Multinational Perspective. 21.

Richards, J. C., \& Rodgers, T. S. (1986). Approaches and methods in language teaching: A description and analysis. Cambridge University Press.

Schunk, D. H. (2012). Learning theories: An educational perspective (6th ed). Pearson. 
Mokhammad Nizzam1

Sierra, F. C., \& de Alcalá, U. (2016). Foreign Language Teaching Methods. Some Issues and New Moves. 23. 